\title{
Sepsis at ICU admission does not decrease 30-day survival in very old patients: a post-hoc analysis of the VIP1 multinational cohort study
}

Mercedes Ibarz ${ }^{1 *}\left(\mathbb{0}\right.$, Ariane Boumendil ${ }^{2}$, Lenneke E. M. Haas ${ }^{3}$, Marian Irazabal ${ }^{4}$, Hans Flaatten ${ }^{5,28}$, Dylan W. de Lange ${ }^{6}$, Alessandro Morandi 7,8 , Finn H. Andersen ${ }^{9,10}$, Guido Bertolini ${ }^{11}$, Maurizio Cecconi ${ }^{12,13}$, Steffen Christensen ${ }^{14}$, Loredana Faraldi ${ }^{15}$, Jesper Fjølner ${ }^{14}$, Christian Jung ${ }^{16}$, Brian Marsh ${ }^{17}$, Rui Moreno ${ }^{18}$, Sandra Oeyen ${ }^{19}$, Christina Agwald Öhman ${ }^{20}$, Bernardo Bollen Pinto ${ }^{21}$, Ivo W. Soliman ${ }^{6}$, Wojciech Szczeklik ${ }^{22}$, Andreas Valentin ${ }^{23}$, Ximena Watson ${ }^{24}$, Tilemachos Zaferidis ${ }^{25}$, Bertrand Guidet ${ }^{2,26}$, Antonio Artigas ${ }^{1,4,27}$ and the VIP1 study

\begin{abstract}
Background: The number of intensive care patients aged $\geq 80$ years (Very old Intensive Care Patients; VIPs) is growing. VIPs have high mortality and morbidity and the benefits of ICU admission are frequently questioned. Sepsis incidence has risen in recent years and identification of outcomes is of considerable public importance. We aimed to determine whether VIPs admitted for sepsis had different outcomes than those admitted for other acute reasons and identify potential prognostic factors for 30-day survival.

Results: This prospective study included VIPs with Sequential Organ Failure Assessment (SOFA) scores $\geq 2$ acutely admitted to 307 ICUs in 21 European countries. Of 3869 acutely admitted VIPs, 493 (12.7\%) [53.8\% male, median age 83 (81-86) years] were admitted for sepsis. Sepsis was defined according to clinical criteria; suspected or demonstrated focus of infection and SOFA score $\geq 2$ points. Compared to VIPs admitted for other acute reasons, VIPs admitted for sepsis were younger, had a higher SOFA score ( 9 vs. 7, $p<0.0001$ ), required more vasoactive drugs [ $82.2 \%$ vs. $55.1 \%, p<0.0001]$ and renal replacement therapies [17.4\% vs. 9.9\%; $p<0.0001]$, and had more life-sustaining treatment limitations [37.3\% vs. 32.1\%; $p=0.02$ ]. Frailty was similar in both groups. Unadjusted 30-day survival was not significantly different between the two groups. After adjustment for age, gender, frailty, and SOFA score, sepsis had no impact on 30-day survival [HR 0.99 (95\% Cl 0.86-1.15), $p=0.917]$. Inverse-probability weight (IPW)-adjusted survival curves for the first 30 days after ICU admission were similar for acute septic and non-septic patients [HR: 1.00 (95\% Cl $0.87-1.17), p=0.95]$. A matched-pair analysis in which patients with sepsis were matched with two control patients of the same gender with the same age, SOFA score, and level of frailty was also performed. A Cox proportional hazard regression model stratified on the matched pairs showed that 30-day survival was similar in both groups [57.2\% (95\% Cl 52.7-60.7) vs. 57.1\% (95\% Cl 53.7-60.1), $p=0.85]$.
\end{abstract}

Conclusions: After adjusting for organ dysfunction, sepsis at admission was not independently associated with decreased 30-day survival in this multinational study of 3869 VIPs. Age, frailty, and SOFA score were independently associated with survival.

\footnotetext{
*Correspondence: mibarzvillamayor@gmail.com

${ }^{1}$ Department of Intensive Care Medicine, Hospital Universitario Sagrat

Cor, Viladomat 288, 08029 Barcelona, Spain

Full list of author information is available at the end of the article
} in this article are included in the article's Creative Commons licence, unless indicated otherwise in a credit line to the material. If material is not included in the article's Creative Commons licence and your intended use is not permitted by statutory regulation or exceeds the permitted use, you will need to obtain permission directly from the copyright holder. To view a copy of this licence, visit http://creativeco mmons.org/licenses/by/4.0/. 
Keywords: Sepsis, Very old, Intensive care, Severity of illness, Outcome, Survival, Mortality

\section{Introduction}

The proportion of patients aged $\geq 80$ years admitted to intensive care units (ICU), so-called Very Old Intensive Care Patients (VIPs), is growing fast due to ageing of the population [1]. Nowadays, VIPs represent $10 \%$ to $20 \%$ of all ICU admissions [2-7].

Infection is one of the most frequent reasons for acute ICU admission of older patients, with increasing incidences over the last decades [8-13]. Sepsis develops when the host's response to infection becomes dysregulated and leads to life-threatening organ dysfunction [14]. Older patients account for a small proportion of the overall population, but a large proportion of sepsis cases; about $60 \%$ of septic patients are aged $>65$ years. The incidence of sepsis increases with age and increases steeply in persons aged $\geq 80$ years [8-10]. Very old persons are at particularly high risk due to pre-existing comorbidities, impaired immune function (immunosenescence), sarcopenia, decrease in reserve capacities related to ageing, and many times malnutrition and polypharmacy $[8-10,15]$. Moreover, mortality rates in VIPs with sepsis are high, with an estimated ICU mortality of 50\% to $60 \%$ [6], reaching $92 \%$ at 6 months in those with circulatory failure [16]. In addition, survivors are at increased risk of developing cognitive impairment and functional disabilities, estimated at $16 \%$ to $40 \%$ [17-19].

The relatively high risk of mortality and shorter life expectancy amongst VIPs with sepsis, combined with increasing pressure on healthcare facilities including ICUs, result in uncertainty about the appropriateness of admitting VIPs with sepsis to ICUs, especially if they are frail or have severe comorbidities. Given the goal of longterm survival with a satisfactory quality of life (QoL) according to patients' expectations, it is often difficult to predict the benefits of ICU treatment in VIPs, [19, 20]. To determine whether VIPs with sepsis should be admitted to ICUs, healthcare providers need more information about outcomes and risk factors [21].

We aimed to determine whether VIPs admitted with sepsis had a different 30-day outcome than VIPs admitted for other acute reasons and to identify potential prognostic factors for 30-day survival.

\section{Materials and methods}

\section{Study design and setting}

The present study is a post-hoc analysis of the VIP1 multinational cohort study [1]. Patients with sepsis were identified as a group of interest and before the end of the VIP1 study, we decided to analyse the cohort of VIPs admitted for sepsis versus VIPs admitted for another acute reason.

In brief, the VIP1 study was a prospective observational study to measure outcomes in patients aged $\geq 80$ years in 311 ICUs in 21 European countries. Each participating ICU included the first consecutive 20 VIPs admitted within a 3-month inclusion period; data were collected between October 2016 and May 2017. A website was designed to provide information about the study and to enable data entry using an electronic case record form; the electronic case record form and database ran on a secure server at Aarhus University, Denmark. The study was registered at ClinicalTRials.gov (ID: NCTO3134807).

\section{Participants}

From the original VIP1 study, only acute admissions in patients $\geq 80$ years of age were eligible. We excluded patients admitted for postoperative care after planned surgery; all the other 11 reasons for acute ICU admissions were accepted (Additional file 1: Table S1).

\section{Study variables and data collection}

Demographic and clinical characteristics were recorded for all patients, including age, gender, hospital length of stay (LOS) prior to ICU admission, LOS in ICU, SOFA score at admission [22], and frailty measured with the Clinical Frailty Scale (CFS) [23].

The main outcome variable was survival in the 30 days following ICU admission. We also recorded the use of the following: invasive mechanical ventilation, non-invasive ventilation, vasoactive drugs, renal replacement therapies (RRT), and orders to withhold or withdraw life-sustaining treatment (LST).

\section{Definitions \\ Admission categories}

The most appropriate clinical reason for ICU admission was chosen by the site investigator from a predefined list of 11 acute categories (respiratory failure, circulatory failure, combined respiratory/circulatory failure, sepsis, severe trauma without head injury, severe trauma with head injury, isolated head injury, intoxication, non-traumatic brain injury, postoperative care after emergency surgery, or other) (Additional file 1: Table S1).

\section{Severe sepsis admission category}

Patients were included in sepsis category according to clinical criteria. 
Clinical criteria adopted since 2015 are suspected or documented infection and an acute increase of $\geq 2$ SOFA points (a proxy for organ dysfunction) ". It was updated in 2016 in sepsis-3 criteria [14]: "Sepsis is a life-threatening organ dysfunction caused by a dysregulated host response to infection. For clinical operationalisation, organ dysfunction can be represented by an increase in the Sequential [Sepsis-related] Organ Failure Assessment (SOFA) score of 2 points or more, which is associated with a in-hospital mortality greater than $10 \%$ ".

\section{Frailty}

It was assessed according to the Clinical Frailty Scale [23]. This scale is composed of nine classes from very fit to terminally ill (Additional file 2: Figure S1). We determined the frailty level present before hospital admission and not affected by the acute illness. Patients were classified according to the CFS as "fit" (CFS $\leq 3)$, "vulnerable" $(\mathrm{CFS}=4)$, or "frail" (CFS $\geq 5)$.

\section{Statistical analysis}

No formal sample-size calculation was performed for this observational study. Nevertheless, with the number of subjects included in our sample, to test whether the hazard ratio of septic vs non-septic patients is equal to 1.5 , the power is 99 . To test whether survival of septic is equivalent to that of non-septic patients, the power is 99 .

We compared baseline characteristics, treatment, and outcomes between septic and non-septic VIPs. We expressed categorical variables as frequencies and percentages, and continuous variables as medians and interquartile ranges. There are no missing values amongst the variables used in the analysis, except for 2 patients with missing date of ICU discharge. To compare groups, we used Chi square tests for categorical variables and the Mann-Whitney $U$ test for continuous variables.

To study 30-day survival, all patients were censored at day 30. For patients discharged from the ICU and dead at day 30, the precise date of death is unknown; for those, we assumed that the survival time was the middle of the interval between date of discharge and day 30 . This midpoint imputation is a simple method to deal with interval-censored data and has been shown to give similar estimates than more advanced methods [24].

Unadjusted survival curves were estimated using the standard Kaplan-Meier estimator and compared between groups by means of a log-rank test.

To estimate associations between variables and survival 30 days after ICU admission, we used a Cox proportional hazard regression model. To check the proportionality assumption for each covariate, we plotted the scaled Schoenfeld residuals against time along with smooth curves and detected no violation of the assumption.
Inverse probability weights (IPW) were used to produce survival curves adjusted for covariates [25]. The weights were estimated using the same covariates included in the Cox model, namely frailty, age, gender, type of admission (septic vs. non-septic), and SOFA score to estimate the weights. Informally, each subject is weighted by the inverse of the probability of having sepsis or not conditionally on the covariates.

We also performed a matched-pair analysis. For each septic patient, we identified a non-septic patient of the same age, gender, level of frailty, and an SOFA score equal to that of the septic patient plus or minus 0.1 . To estimate associations between sepsis and survival at 30 days after ICU admission in the matched sample, we used a Cox proportional hazard regression model stratified on the matched pairs. We plotted the Kaplan-Meier survival curves of septic and non-septic patients in the matched sample and used the usual log-rank test to compare the curves [26].

$P$ values less than 0.05 were considered statistically significant. All analyses were performed with $\mathrm{R}$ software, version 3.2.2 ( $\mathrm{R}$ foundation for Statistical computing).

\section{Results \\ Participants}

The VIP1 study included 5132 VIPs; 5021 (98\%) completed the 30-day follow-up. Amongst patients who completed the 30-day follow-up, we excluded the 906 (18\%) admitted primarily for postoperative care after elective surgery. Moreover, we excluded 246 (4.9\%) patients with Sequential (Sepsis-related) Organ Failure Assessment (SOFA) score $<2$; thus, we analysed data from 3869 patients (Fig. 1). Regions and countries of the included patients are listed (Additional file 3: Table S2).

\section{Patient characteristics}

We included 3869 VIPs [median age 84 (82-86) years; 2013 (52\%) male; median SOFA score 8 (5-11); $47 \%$ frail; $32.8 \%$ with limitations on LST] admitted as acute patients to 307 ICUs in 21 countries in the context of the multicentre VIP-1 study. LOS before ICU was 1 day (0-3) (see Table 1).

The median number of patients recruited per country was 143 (range 3-719), and the median number of patients per ICU was 13 (range 1-67).

\section{Comparison between VIPs admitted for sepsis and those admitted for other acute reasons}

Patients admitted for sepsis accounted for $12.7 \%$ (493/3869); there was no gender difference, but the sepsis group were younger, had a higher SOFA score on admission, more often received vasoactive drugs and RRT, but were less frequently given mechanical ventilation and 


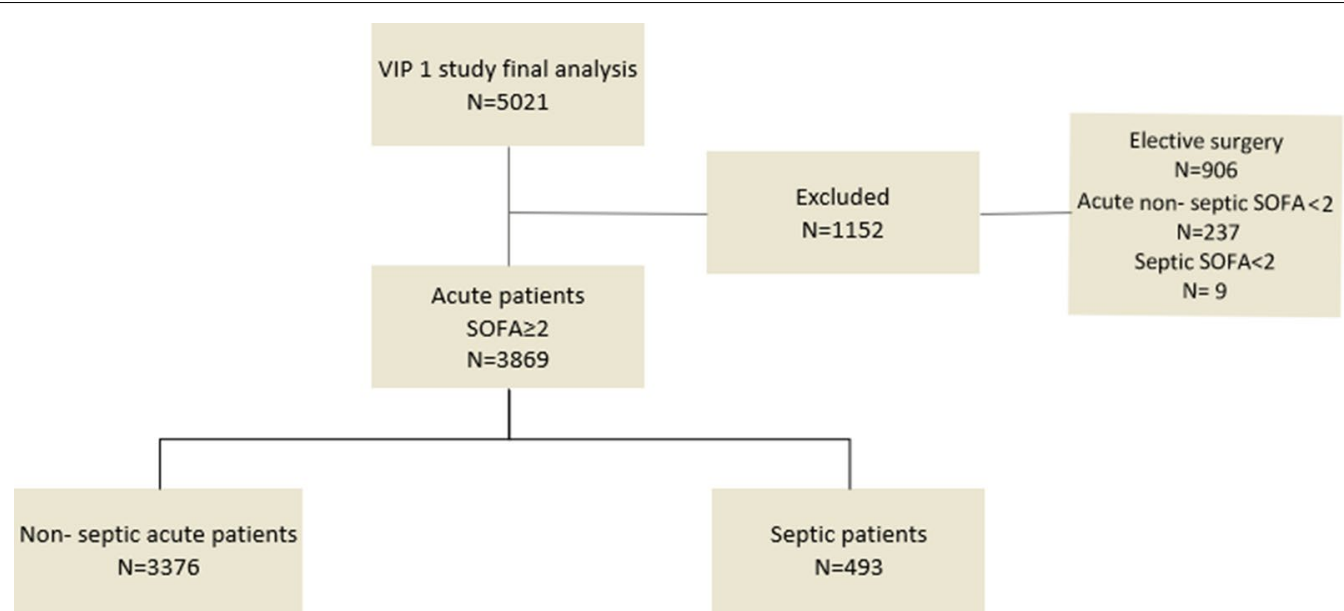

Fig. 1 Study flowchart. VIP1 study [1]. Septic patients: patients admitted to ICU for sepsis; non-septic patients: patients admitted to ICU for another acute reason. SOFA Sequential Organ Failure Assessment

Table 1 Comparison of acute patients admitted for sepsis versus acute patients admitted for other reason

\begin{tabular}{|c|c|c|c|c|}
\hline Admission category & All acute patients & Other categories & Sepsis & $p$ value \\
\hline$N(\%)$ & $3869(100 \%)$ & $3376(87.3 \%)$ & $493(12.7 \%)$ & \\
\hline Age $(\text { years })^{a}$ & $84(82-86)$ & $84(82-87)$ & $83(81-86)$ & $<0.0001$ \\
\hline Gender (male) & $2013(52 \%)$ & $1748(51.8 \%)$ & $265(53.8 \%)$ & 0.4402 \\
\hline Hospital LOS before ICU (days) ${ }^{\text {a }}$ & $1(0-3)$ & $1(0-3)$ & $1(0-3)$ & 0.4600 \\
\hline SOFA score at admission ${ }^{\mathrm{a}}$ & $8(5-11)$ & $7(5-11)$ & $9(6-12)$ & $<0.0001$ \\
\hline ICU LOS (days) ${ }^{\mathrm{a}}$ & $2.96(1.17-6.81)$ & $2.88(1.12-6.67)$ & $3.54(1.5-8)$ & 0.0036 \\
\hline \multicolumn{5}{|l|}{ Frailty (CFS) } \\
\hline Fit (CFS 1-3) & 1331 (34.4\%) & $1166(34.5 \%)$ & $165(33.5 \%)$ & 0.0737 \\
\hline Vulnerable (CFS 4) & $719(18.6 \%)$ & $643(19 \%)$ & $76(15.4 \%)$ & \\
\hline Frail (CFS 5-9) & $1819(47 \%)$ & $1567(46.4 \%)$ & $252(51.1 \%)$ & \\
\hline Fit or vulnerable & $2050(53 \%)$ & $1809(53.6 \%)$ & $241(48.9 \%)$ & 0.0568 \\
\hline Frail & $1819(47 \%)$ & $1567(46.4 \%)$ & $252(51.1 \%)$ & \\
\hline \multicolumn{5}{|l|}{ Interventions in ICU } \\
\hline At least 1 intervention & $3196(82.6 \%)$ & $2760(81.8 \%)$ & $436(88.4 \%)$ & 0.0003 \\
\hline No interventions & $673(17.4 \%)$ & $616(18.2 \%)$ & $57(11.6 \%)$ & \\
\hline Mechanical ventilation & 2087 (53.9\%) & $1853(54.9 \%)$ & $234(47.5 \%)$ & 0.0024 \\
\hline Non-invasive ventilation & $1047(27.1 \%)$ & $939(27.8 \%)$ & $108(21.9 \%)$ & 0.0069 \\
\hline Vasoactive drugs & $2265(58.5 \%)$ & $1860(55.1 \%)$ & $405(82.2 \%)$ & $<0.0001$ \\
\hline RRT & $421(10.9 \%)$ & $335(9.9 \%)$ & $86(17.4 \%)$ & $<0.0001$ \\
\hline \multicolumn{5}{|c|}{ Life-sustaining treatment limitations } \\
\hline No LST limitations & $2601(67.2 \%)$ & $2292(67.9 \%)$ & $309(62.7 \%)$ & 0.0243 \\
\hline LST limitations & $1268(32.8 \%)$ & $1084(32.1 \%)$ & $184(37.3 \%)$ & \\
\hline Withholding & $679(17.5 \%)$ & $571(16.9 \%)$ & $108(21.9 \%)$ & 0.0196 \\
\hline Withdrawing \pm withholding & $589(15.2 \%)$ & $513(15.2 \%)$ & $76(15.4 \%)$ & \\
\hline \multicolumn{5}{|l|}{ Outcome } \\
\hline ICU mortality & $1072(27.7 \%)$ & $918(27.2 \%)$ & $154(31.2 \%)$ & 0.0686 \\
\hline 30-day mortality & $1577(40.8 \%)$ & $1357(40.2 \%)$ & $220(44.6 \%)$ & 0.0687 \\
\hline
\end{tabular}

LOS length of stay, SOFA Sequential Organ Failure Assessment, CFS Clinical Frailty Scale, RRT renal replacement therapy, LST Life-sustaining treatment

a Expressed as median, IQR

No missing values except for length of ICU stay; 2 patients had a missing date of discharge 
NIV. Limitations of life-sustaining treatment (LST) were more frequently performed, and LOS was increased in patients admitted with sepsis (Table 1).

\section{Unmatched analysis}

No significant differences between groups were observed in survival after ICU admission $(p=0.1)$; survival at day 4 was $78.2 \%$ (95\% CI 74.6-82.0) in septic patients vs. $82.8 \%$ (95\% CI 81.5-84.1) in non-septic patients and survival at day 30 was $54.8 \%$ (95\% CI 50.5-59.5) in septic patients vs. $57.8 \%$ (95\% CI 56.1-59.5) in non-septic VIPs; HR for septic vs. non-septic patients was 1.13 (95\% CI 0.98-1.3), $p=0.0986$. After adjustment for age, frailty, gender, and SOFA score, sepsis had no effect on survival after ICU admission [HR: 0.99 (95\% CI $0.86-1.15), p=0.917]$ (Table 2A).

Inverse-probability weight (IPW)-adjusted survival curves for the first 30 days after ICU admission were similar for septic and non-septic patients [HR: 1.00 (95\% CI 0.87-1.17), $p=0.947$ ] (Fig. 2b).

Inverse-probability weight (IPW) survival curves for quartiles of the SOFA score in septic and non-septic patients showed no significant differences (Additional file 4: Figure S2).

\section{Matched analysis}

Likewise, 30-day survival in the matched sample (443 septic patients vs. 824 patients without sepsis, 62 patients had only one match and 55 could not be matchedTable 3) was similar in septic and non-septic VIPs [57.2\% (95\% CI 52.7-60.7) vs. 57.1\% (95\% CI 53.7-60.1); HR: 1.02 (95\% CI 0.85-1.22), $p=0.854$ ] (Fig. 2c).

Prognostic factors of survival in all acute admitted patients In the multivariate analysis, age, frailty, and SOFA score were independently associated with survival, but sepsis was not (Table 2A).

Separate analyses for septic and non-septic patients yielded similar results (Table $2 \mathrm{~B}, \mathrm{C}$ ).

A possible centre effect was assessed comparing the log partial likelihood of a model including only sepsis and that of the same model integrating a random centre effect. The $p$ value for the random effect was $<0.001$ suggesting a significant random effect across centre. We thus built a Cox model using the same variables and integrating a random centre effect. The coefficients and degree of significance of the parameters are comparable to those of the model without random effect (Additional file 5: Table S3).

\section{Discussion}

We found that the 30-day survival rate in patients with sepsis was similar to the survival of patients admitted for another acute reason. Sepsis, after adjusting for organ dysfunction, did not significantly influence. Age, frailty, and SOFA score were the independent factors associated

Table 2 Factors affecting 30 -day survival of ICU patients aged $\geq 80$ years with SOFA $\geq 2$ at admission, multivariate analysis

\begin{tabular}{|c|c|c|}
\hline & $\mathrm{HR}(95 \% \mathrm{Cl})$ & $p$ value \\
\hline \multicolumn{3}{|c|}{ A. Results of the Cox analysis considering all acutely admitted patients ( $n=3869$ ) } \\
\hline Sepsis & $0.99(0.86-1.15)$ & $p=0.9173$ \\
\hline Age (per 5-year increase) & $1.16(1.09-1.25)$ & $p<0.0001$ \\
\hline Frailty: vulnerable vs. fit & $1.16(1-1.35)$ & $p=0.0556$ \\
\hline Frailty: frail vs. fit & $1.47(1.31-1.66)$ & $p<0.0001$ \\
\hline Male vs. female & $1.16(1.05-1.28)$ & $p=0.0043$ \\
\hline SOFA score (per one-point increase) & $1.13(1.12-1.14)$ & $p<0.0001$ \\
\hline \multicolumn{3}{|c|}{ B. Results of the Cox analysis considering only acute patients admitted for sepsis $(n=493)$} \\
\hline Age (per 5-year increase) & $1.33(1.1-1.61)$ & $p=0.0029$ \\
\hline Frailty: vulnerable vs. fit & $1.54(1.02-2.34)$ & $p=0.0416$ \\
\hline Frailty: frail vs. fit & $1.47(1.07-2.02)$ & $p=0.0182$ \\
\hline Male vs. female & $1.12(0.85-1.47)$ & $p=0.4202$ \\
\hline SOFA score (per one-point increase) & $1.13(1.1-1.17)$ & $p<0.0001$ \\
\hline \multicolumn{3}{|c|}{ C. Results of the Cox analysis considering only acute patients admitted for other reason than sepsis $(n=3376)$} \\
\hline Age (per 5-year increase) & $1.14(1.06-1.23)$ & $p=0.0005$ \\
\hline Frailty: vulnerable vs. fit & $1.11(0.95-1.31)$ & $p=0.1939$ \\
\hline Frailty: frail vs. fit & $1.48(1.31-1.68)$ & $p<0.0001$ \\
\hline Male vs. female & $1.16(1.04-1.3)$ & $p=0.0064$ \\
\hline SOFA score (per one-point increase) & $1.13(1.12-1.14)$ & $p<0.0001$ \\
\hline
\end{tabular}




\section{a}



b

Days after ICU admission

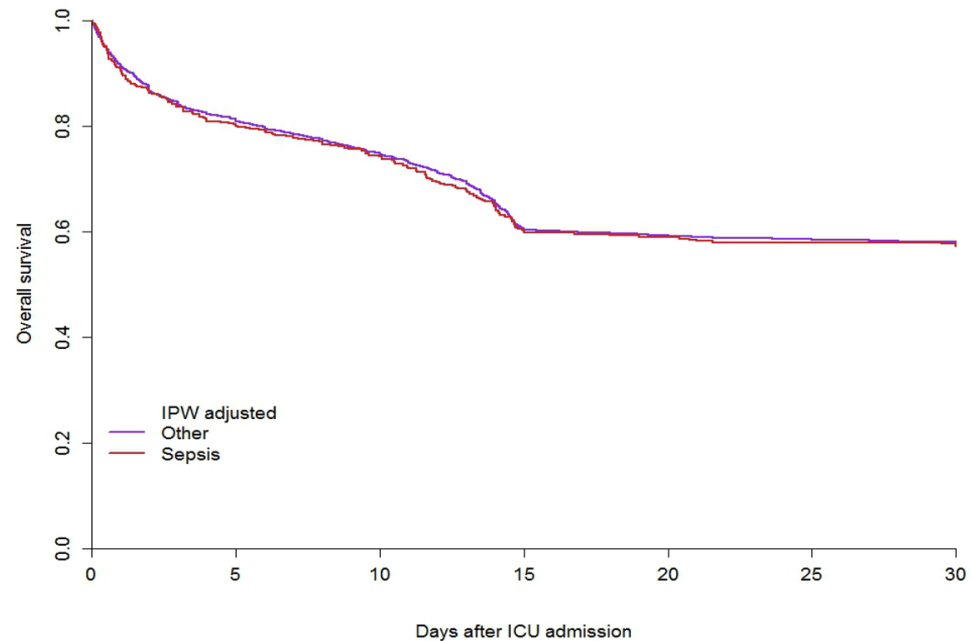

c



Fig. 2 Kaplan-Meyer survival curves in septic and acute non-septic patients. a Non-adjusted. b Inverse-probability weight (IPW)-adjusted overall survival (the weights were estimated using frailty, age, gender, type of admission, and SOFA score). c Matched cohort survival analysis 
Table 3 Description of the matched sample

\begin{tabular}{|c|c|c|c|}
\hline Admission category & Other categories & Sepsis & $p$ value \\
\hline$N$ & 824 & 443 & \\
\hline Age (years) ${ }^{a}$ & $82(81-85)$ & $83(81-85)$ & 0.5618 \\
\hline Gender (male) & $435(52.8 \%)$ & $233(52.6 \%)$ & 0.9941 \\
\hline $\begin{array}{l}\text { Hospital LOS before ICU } \\
\text { admission (days) }\end{array}$ & $1(0-3)$ & $1(0-3)$ & 0.28 \\
\hline $\begin{array}{l}\text { SOFA score at } \\
\text { admission }^{a}\end{array}$ & $8(6-11)$ & $8(6-12)$ & 0.5468 \\
\hline ICU LOS (days) ${ }^{\mathrm{a}}$ & $3.29(1.33-7.85)$ & $3.88(1.67-8.53)$ & 0.2454 \\
\hline Frailty (CFS) & & & 0.6963 \\
\hline Fit (CFS 1-3) & $273(33.1 \%)$ & $144(32.5 \%)$ & \\
\hline Vulnerable (CFS 4) & 105 (12.7\%) & $64(14.4 \%)$ & \\
\hline Frail (CFS 5-9) & $446(54.1 \%)$ & $235(53 \%)$ & \\
\hline \multicolumn{4}{|c|}{ Therapeutic interventions in ICU } \\
\hline At least one & $723(87.7 \%)$ & $389(87.8 \%)$ & 0.999 \\
\hline Mechanical ventilation & $480(58.3 \%)$ & $202(45.6 \%)$ & $<0.0001$ \\
\hline Non-invasive ventilation & $239(29 \%)$ & $100(22.6 \%)$ & 0.0164 \\
\hline Vasoactive drugs & $500(60,7 \%)$ & $361(81.5 \%)$ & $<0.0001$ \\
\hline RRT & $115(14 \%)$ & $77(17.4 \%)$ & 0.1238 \\
\hline \multicolumn{4}{|c|}{ Life-sustaining treatment limitations } \\
\hline No LST limitations & $568(68.9 \%)$ & $286(64.6 \%)$ & 0.1284 \\
\hline LST limitations & $256(31.1 \%)$ & $157(35.4 \%)$ & \\
\hline Withholding & $128(15.5 \%)$ & $98(22.1 \%)$ & 0.0124 \\
\hline $\begin{array}{l}\text { Withdrawing } \pm \text { with- } \\
\text { holding }\end{array}$ & 128 (15.5\%) & $59(13.3 \%)$ & \\
\hline ICU mortality & $239(29 \%)$ & $126(28.4 \%)$ & 0.8841 \\
\hline 30-day mortality & 337 (40.9\%) & $187(42.2 \%)$ & 0.6942 \\
\hline
\end{tabular}

443 patients with sepsis were matched to 824 patients without sepsis 62 patients had only one match and 55 could not be matched Survival was similar; sepsis HR $1.02(95 \% \mathrm{Cl} 0.85-1.22), p=0.854$ LOS length of stay, SOFA Sequential Organ Failure Assessment, CFS Clinical Frailty Score, $R R T$ renal replacement therapy, $L S T$ life-sustaining treatment

a Expressed in median, IQR

with 30-day survival in patients admitted to ICU for sepsis, similar to all acute VIPs with SOFA $\geq 2$. This probably indicates that severity of illness (as expressed by the SOFA score) is the factor that predicts survival independently of whether it is due to sepsis or to other reasons. Therefore, admission for sepsis should not be a factor to limit an ICU admission in this old population.

We collected data from a large cohort in 307 ICUs from 21 European countries. Sepsis was the main reason for admission in $12.7 \%$ of the VIPs, a rate similar to those reported in previous studies $(9-12 \%)[8,15,19$, $20,27]$. Our sample was slightly different to the one analysed in the original VIP1 study, because we excluded the subgroup of patients admitted after planned surgery and compared all acute admissions with the sepsis subgroup. This might explain changes in the results, and in the significance of the lack of variable gender in the present analysis. The original VIP1 paper was designed to study the occurrence of frailty and to assess its impact on 30-day mortality in patients 80 years of age or older admitted to European ICUs. The secondary objective was to report the intensity of care and treatment restrictions whilst in the ICU in this patient group. The original VIP-1 study demonstrated an inverse relation between frailty and 30-day mortality and high mortality rates for VIPs admitted to the ICU with sepsis. We studied and better characterised the subgroup of very old septic patients, identifying the variables associated with outcome, reinforcing that frailty and severity of illness (SOFA) as well as age, and are the determinant factors affecting outcome in VIPs admitted for sepsis. Moreover, we confirmed that sepsis at admission was not a determinant factor on outcome in this population with the analysis of a matched sample with septic and non-septic patients.

Our results are important because relatively few welldesigned studies have addressed the impact of sepsis in older patients. Reported ICU-survival rates amongst octogenarians with sepsis vary widely $[6,16,27,28]$, and the risk factors for mortality in these patients have not been completely elucidated. A recent systematic review including 4256 patients aged $\geq 80$ years from 18 studies [29] reported mortality rates of $43 \%$ in the ICU, $47 \%$ in the hospital, and 68\% 1 year after ICU admission. Reported rates for 30-day mortality range from 30 [27] to $50 \%[6,29]$.

To our knowledge, this is the first study to compare frequencies of therapeutic interventions, limitations on life-supporting treatments, risk factors for mortality, and outcomes between VIPs admitted with sepsis and those admitted for other acute reasons. In the present study, elective surgical patients were excluded because various other publications [23, 28-32] demonstrated that such patients have a better outcome with much lower mortality rates.

Previous studies reported that limitations on lifesustaining treatment were applied more frequently and earlier in aged patients than in younger patients [27], and moreover, limitations on LST often preceded VIPs' death in the $\operatorname{ICU}[27,33,34]$. However, the intensity of treatment in VIPs has increased over time, and this increase has been associated with a decrease in mortality adjusted for severity [3]. The incidence of LST limitations reported in recent studies ranges from 10 to $27 \%$, being higher in aged patients and reaching $41.6 \%$ in very old, frail patients [33-36]. Guidet et al. [37] studied decisions to limit LST in the VIP-1 cohort and demonstrated that acute admission, frailty, age, SOFA score at admission, and country were associated with the application of limitations. We found that patients admitted for sepsis received more therapeutic interventions, mainly vasoactive drugs and RRT. Decisions to 
limit LST (mainly as withholding therapy) were more common in septic patients (22\% vs $17 \%)$ and this could be explained because they were frailer and had more organ dysfunction.

Our study's strengths include its large prospective sample, multicentre design, international participation, and acutely admitted non-septic control group. Furthermore, recruiting all patients prospectively in a period of 8 months reduced time bias.

Our study, however, has several limitations. First, data in VIP1 study were prospectively collected [1] but the data analysis on septic patients was retrospectively done after closure of the database of the original study. Second, admission categories were mutually exclusive and the site investigator in every centre decided to include the patient in one or another category according to the main diagnosis. Severe sepsis was defined according to clinical criteria [14] and we must assume that the individual ICUs appropriately used this definition. However, we cannot fully exclude that some patients may have been misclassified, for example as acute circulatory or respiratory failure. In other words, patients with acute or respiratory failure may also have had a sepsis.

Third, we were not able to analyse the subgroup of patients with septic shock since lactate levels were not available in the registry. Anyhow, $82.2 \%$ of the septic patients received vasopressors to maintain a mean arterial pressure of $65 \mathrm{mmHg}$ and mean SOFA at admission was 9. Fourth, the focus of infection was not registered and occurrence of sepsis after ICU admission was neither reported. Fifth, we have no data about patients who were not admitted to the ICU due to triage decisions. Sixth, we did not analyse reasons for LST limitations, because it was not the aim of the study, it is fully analysed in another article [36]. Seventh, the only datum about prior health status recorded was frailty, so no information about comorbidities or previous cognitive status was available. And last, no follow-up of the patients was performed.

Nevertheless, our results provide insight into the outcome and factors associated with 30-day survival in VIPs admitted for sepsis in comparison to VIPs admitted for other acute reasons. The fact that sepsis at admission, after adjusting for organ dysfunction, was not independently associated with survival suggests that the best option today is assessing very old patients according to their age, frailty, and severity of illness, independently of their diagnostic category. Once admitted to ICU, we can establish goals of care and reassess the intensity of therapeutic interventions after a reasonable period of time, according to response to treatment, expected outcomes, and patient/family wishes [38].

\section{Conclusion}

Mortality 30 days after ICU admission is high in very old patients admitted with sepsis. However, we did not find admission for sepsis to be an independent risk factor for decreased survival. Frailty, older age, and higher SOFA score at admission were the significant factors associated with decreased 30-day survival in this population. Therefore, sepsis at admission should not be the only determining factor either in the decision of admission to the ICU or in the establishment of LST in very elderly patients.

Future research is required to optimise care for these patients. We also need more information about longterm survival and quality of life in VIPs admitted for sepsis and a reliable risk prediction model.

\section{Supplementary information}

Supplementary information accompanies this paper at https://doi. org/10.1186/s13613-020-00672-w.

Additional file 1: Table S1. Admission acute categories SOFA $\geq 2$.

Additional file 2: Figure S1. Clinical Frailty Scale (CFS).

Additional file 3: Table S2. Information about region and country of the included patients.

Additional file 4: Figure S2. Inverse probability weighted survival curves for quartiles of the SOFA SCORE.

Additional file 5: Table S3. Results of the Cox analysis integrating a random centre effect.

\section{Abbreviations}

ICU: Intensive care unit; VIPs: Very Old Intensive Care Patients; RRT: Renal replacement therapy; SOFA: Sequential Organ Failure Assessment; CFS: Clinical Frailty Scale; LOS: Length of stay; LST: Life-sustaining treatment; QoL: Quality of life.

\section{Acknowledgements}

VIP1 study contributors: René Schmutz, B5, Hospital of St. John of God Vienna, Austria; Franz Wimmer, Interne Intensiv, Kardinal Schwarzenberg'sches Krankenhaus, Austria; Philipp Eller, Intensivstation der Univ.-Klinik für Innere Medizin, Medical University Graz, Austria; Michael Joannidis, MICU, University Hospital Innsbruck, Austria; Pieter De Buysscher, Department of Intensive Care, AZ Sint-Lucas Ghent, Belgium; Nikolaas De Neve, Department of Intensive Care, O.L.Vrouwhospital Aalst, Belgium; Sandra Oeyen, Department of Intensive Care, Ghent University Hospital, Belgium; Walter Swinnen, Department of Intensive Care Medicine, AZ Sint-Blasius Dendermonde, Belgium; Bernardo Bollen Pinto, Peri-Interventional Intermediate Care (SINPI), Geneva University Hospitals, Switzerland; Paul Abraham, Adult Intensive Care (SIA), Geneva University Hospitals, Switzerland; Leila Hergafi, Service des Soins intensifs, Hôpital Fribourgeois, Fribourg, Switzerland; Joerg C. Schefold, Universitätsklinik für Intensivmedizin, Inselspital, Bern University Hospital, University of Bern, Switzerland; Ewelina Biskup, Medical ICU, University Hospital Basel, Switzerland; Petr Piza, KARIP, IKEM, Czech Republic.; loannis Taliadoros, CY001, Nicosia General Hospital, Cyprus; Jesper Fjølner, ITA, Randers Regional Hospital, Denmark; Nilanjan Dey, Intensiv Herning, Regions Hospital Herning, Denmark; Christoffer Sølling, I-25, Regionshospital Viborg, Denmark; Bodil Steen Rasmussen, ICU, Aalborg University Hospital, Denmark; Steffen Christensen, OPI Ost, Aarhus University Hospital Skejby, Denmark; Xavier Forceville, Réanimation médico chirurgical, Centre Hospitalier de Meaux, France; Guillaume Besch, Département d’Anesthésie Réanimation Chirurgicale, Centre Hospitalier Régional Universtaire de Besançon, France; Herve Mentec, Service de Réanimation Polyvalente, Centre Hospitalier Victor Dupouy Argenteuil, France; Philippe Michel, Réanimation médico-chirurgicale, $\mathrm{CH}$ Carnelle - Portes de I'Oise, France; Philippe Mateu, Réanimation Polyvalente, 
CH de Charleville-Mézières, France; Philippe Michel, Réanimation médicochirurgicale, CH René Dubos, France; Lucie Vettoretti, Réanimation Médicale, CHRU de Besançon, France; Jeremy Bourenne, Reanimation des Urgences et Médicale, CHU Marseille - Timone, France; Nathalie MARIN, reanimation médicale, hopital cochin, France; Max Guillot, Réanimation médicale, Hôpital de Hautepierre, France; Nadia Aissaoui, Réanimation médicale, hopital européen georges pompidou, France; Cyril Goulenok, Réanimation Médicale, Hopital Privé Jacques CARTIER, France; Nathalie Thieulot-Rolin, Intensive care medicine department, Hospital Marc Jacquet 77,000 Melun, France; Jonathan Messika, Réanimation Médico-Chirurgicale, Louis Mourier, France; Lionel Lamhaut, Polyvalente adult ICU, Necker (APHP), France; Bertrand Guidet, Réanimation médicale, Saint Antoine, France; Cyril Charron, Medical-surgical ICU, University Hospital Ambroise Paré, de Paris Boulogne-Billancourt, France, France; Alexander Lauten, 1) Department of Cardiology, 2) DZHK Berlin partner side, Charité Universitaetsmedizin Berlin, Germany; Anna Lena Sacher, Department of Anesthesiology, Charité Universitaetsmedizin Berlin, Germany; Thorsten Brenner, Department of Anesthesiology, Heidelberg University Hospital, Germany; Marcus Franz, Department of Internal Medicine, Jena University Hospital, Friedrich-Schiller University, Germany; Frank Bloos, Department of Anesthesiology, Jena University Hospital, Friedrich-Schiller University, Germany; Henning Ebelt, Department for Medicine II, Catholic Hospital "St. Johann Nepomuk", Germany; Stefan J Schaller, Department of Anesthesiology, Klinikum rechts der Isar, Technical University of Munich, Munich, Germany; Kristina Fuest, Department of Anesthesiology, Klinikum rechts der Isar, Technical University of Munich, Munich, Germany, Germany; Christian Rabe, Department Of Clinical Toxicology, Klinikum rechts der Isar, Technical University of Munich, Munich, Germany, Germany; Thorben Dieck, Department of Anaesthesiology and Intensive Care, Medical School Hospital Hannover, Germany; Stephan Steiner, Department of Cardiology, Pneumology and Intensive Care, St. Vincenz Krankenhaus Limburg, Germany; Tobias Graf, Department of Cardiology, University Heart Center Luebeck, Germany; Amir M Nia, Division of Cardiology and Intensive Care, University Hospital Düsseldorf, Heinrich-Heine University, Germany; Christian Jung, Division of Cardiology and Intensive Care, University Hospital Düsseldorf, Heinrich-Heine University, Germany; Rolf Alexander Janosi, Department of Cardiology and Vascular Diseases, University Hospital Essen, Germany; Patrick Meybohm of the Department of Anaesthesiology, Intensive Care Medicine and Pain Therapy, Frankfurt University Hospital, Frankfurt, Germany; Philipp Simon, Department of Anaesthesiology and ICM, University Hospital of Leipzig, Germany; Stefan Utzolino, Department of General and Visceral Surgery, Universitätsklinikum Freiburg, Germany; Tim Rahmel, Department of Anaesthesiology, Intensive Care Medicine, University Hospital Knappschaftskrankenhaus Bochum Germany; Eberhard Barth, Department of Anaesthesiology, University of UIm, Germany; Christian Jung, University Hospital Düsseldorf, Heinrich-HeineUniversity Düsseldorf, Medical Faculty, Division of Cardiology, Pulmonology and Vascular Medicine, Düsseldorf, Germany, Germany; Michael Schuster, Department of Anaesthesiology, University Hospital Mainz, Germany; Zoi Aidoni, ICU, UGHT AHEPA, Greece; Stavros Aloizos, ICU, Army Share Fund Hospital, Athens, Greece; Polychronis Tasioudis, ICU, G. Gennimatas hospital of Thessaloniki, Greece; Kleri Lampiri, ICU, General Hospital Of Kavala, Greece; Vasiliki Zisopoulou, ICU1, General Hospital Of Larissa, Greece; Ifigenia Ravani, ICU, General hospital of Patras, Greece; Evmorfia Pagaki, ICU, General hospital of Trikala, Greece; Angela Antoniou, ICU, Volos General Hospital, Greece; Theodoros A. Katsoulas, ICU, "Ag Anargyroi" General Hospital, Greece; Aikaterini Kounougeri, ICU, Konstantopouleion General Hospital, Athens, Greece; George Marinakis, ICU, "Korgialenio-Benakio" G. Hospital of Athens, Greece; Fotios Tsimpoukas, ICU, Lamia General Hospital, Greece; Anastasia Spyropoulou, ICU, Panarkadian General Hospital of Tripolis, Greece; Paris Zygoulis, General ICU, University hospital of Larisa, Greece; Aikaterini Kyparissi, ICU, "HIPPOCRATEIO" General Hospital of Athens, Greece; Manish Gupta, MICU, MAX SUPER SPECIALTY HOSPITAL, Vaishali, India; Mohan Gurjar, Department of Critical Care Medicine, Sanjay Gandhi Postgraduate Institute of Medical Sciences, India; Ismail M Maji, MICU, St Johns Medical Colleg Hospital, Bangaluri, India; Ivan Hayes, CUH GICU, Cork University Hospital, Ireland; Brian Marsh, Department of Critical Care Medicine, Mater Misericordiae University Hospital, Ireland; Yvelynne Kelly, General ICU, St. Jamess Hospital, Ireland; Andrew Westbrook, ICU, St. Vincents University Hospital, Ireland; Gerry Fitzpatrick, Tallaght intensive Care, Tallaght Hospital, Ireland; Darshana Maheshwari, UHG ICU, University hospital galway, Ireland; Catherine Motherway, ICU, University Hospital limerick, Ireland; Giovanni Negri, Rianimazione, A.S.S.T. Covets Milanese - Presidio Di Magenta - Rosedale G. Forwardly (Magenta), Italy; Savino Spadaro,
Unit di Terapia Intensiva del Serio di Anestesia, Asiana Ospedaliera Universitaria Sant Anna (Ferrara), Italy; Guisepepe Nattino, Rianimazione generale, ASST Lecco - Ospedale A.Manzoni (Lecco), Italy; Matteo Pedeferri, Rianimazione, AO della Provincia di Lecco - Presidio Ospedaliero S.Leopoldo Mandic, Merate, Italy; Annalisa Boscolo, Giustiniani I e II (Istar), Azienda Ospedaliera di Padova (Padova), Italy; Simona Rossi, Servizio Anestesia Rianimazione, Azienda Ospedaliera G.Salvini - Presidio Ospedaliero di Rho, Italy; Giuseppe Calicchio, Centro di Rianimazione, Azienda Ospedaliera Universitaria San Giovanni di Dio e Ruggi d'Aragona, Italy; Lucia Cubattoli, Rianimazione Generale, Azienda Ospedaliera Universitaria Senese (Siena), Italy; Gabriella Di Lascio, Terapia Intensiva di Emergenza, Azienda Ospedaliero Universitaria Careggi (Firenze), Italy; Maria Barbagallo, UO 2 Anestesia Rianimazione Terapia Intensiva, Azienda Ospedaliero-Universitaria di Parma (Parma), Italy; Francesco Berruto, rianimazione, Ospedale E. Agnelli (Pinerolo), Italy; Daniela Codazzi, Unità Terapia Intensiva, Fondazione IRCCS Istituto Nazionale dei Tumori (Milano), Italy; Andrea Bottazzi, Rianimazione 2, Fondazione IRCCS Policlinico S.Matteo (Pavia), Italy; Paolo Fumagalli, Rianimazione 1, Fondazione Policlinico San Matteo (Pavia), Italy; Giancarlo Negro, Anestesia e Rianimazione 1, Ospedale Francesco Ferrari (Casarano), Italy; Giuseppe Lupi, Servizio Anestesia e Rianimazione, Ospedale Maggiore (Cremona), Italy; Flavia Savelli, Anestesia e Rianimazione - TI 2, Ospedale Maurizio Bufalini (Cesena), Italy; Giuseppe A. Vulcano, Terapia Intensiva, Ospedale Civile Nicola Giannettasio (Rossano), Italy; Roberto Fumagalli, Anestesia e Rianimazione 1, Ospedale Niguarda Ca' Granda (Milano), Italy; Andrea Marudi, Rianimazione Neurorianimazione, Nuovo Ospedale Civile Sant Agostino Estense (Modena), Italy; Ugo Lefons, Terapia intensiva, Ospedale Alta Val d'Elsa (Poggibonsi), Italy; Rita Lembo, Rianimazione generale, Ospedale Castelli di Verbania (Verbania), Italy; Maria Babini, Servizio Anestesia e Rianimazione, Ospedale Civile Lugo (Lugo), Italy; Alessandra Paggioro, Struttura Semplice di Rianimazione e Terapia Intensiva, Ospedale degli Infermi di Biella - ASL BI (Biella), Italy; Vieri Parrini, Anestesia e Rianimazione, Ospedale del Mugello (Borgo San Lorenzo), Italy; Maria Zaccaria, Rianimazione e Terapia Intensiva, Ospedale di Ciriè (Torino), Italy; Stefano Clementi, terapia intensiva polivalente, Ospedale di Sesto San Giovanni (Sesto San Giovanni), Italy; Carmelo Gigliuto, Rianimazione, Ospedale di Vigevano - AziendaOspedaliera della Provincia di Pavia (Vigevano), Italy; Francesca Facondini, Reparto di Rianimazione e Terapia Intensiva, Ospedale Infermi (Rimini), Italy; Simonetta Pastorini, Servizio Anestesia-Rianimazione, Ospedale P. Cosma-AUSL 15 Alta padovana (Camposampiero), Italy; Susanna Munaron, Unità di Terapia Intensiva, Ospedale San Giacomo (Castelfranco Veneto), Italy; Italo Calamai, Rianimazione, Ospedale San Giuseppe (Empoli), Italy; Anna Bocchi, Terapia Intensiva, Ospedale San Luca (Trecenta), Italy; Adele Adorni, Unità di Terapia Intensiva Rianimatoria, Ospedale Valduce (Como), Italy; Maria Grazia Bocci, Centro di Rianimazione, Policlinico Agostino Gemelli (Roma), Italy; Andrea Cortegiani, Unità di Terapia Intensiva Polivalente, Policlinico P. Giaccone. University of Palermo, Italy; Tariana Casalicchio, Terapia Intensiva, Hopedale San Giovanni Bosco (Torino), Italy; Serena Melia, Unità di Terapia Intensiva, Ospedale Santa Maria della Misericordia (Perugia), Italy; Elia Graziani, Unità Operativa Anestesia e Rianimazione, Santa Maria delle Croci (Ravenna), Italy; Massimo Barattini, Rianimazione, Ospedale Santa Maria Nuova (Firenze), Italy; Elisabetta Brizio, Servizio di Rianimazione, Ospedale SS Annunziata, Italy; Maurizio Rossi, UO Anestesia e Rianimazione, Zenda Ospedaliera Sant'Anna Como - Presidio di Manage, Italy; Michael Hahn, ICU, Augend hospital, Norway; Hans Flattens, General ICU, Haukeland University Hospital, Norway; Nicolai Kemmerer, ICU, Kongsberg hospital, Norway; Hans Frank Streiter, ICU, Kristiansund Hospital, Norway; Knut Dybwik, ICU, Nordlandssykehuset Bodo, Norway; Terje Legernaes, ICU, Hamar hospital, Norway; Pål Klepstad, Dept Intensive Care Medicine, St Olavs University Hospital, Norway; Even Braut Olaussen, ICU, Stavanger University Hospital, Norway; Knut Inge Olsen, ICU, Namsos Hospital, Norway; Ole Marius Brresen, ICU, Telemark Hospital, Skien, Norway; Geir Bjorsvik, ICU, University Hospital Tromso, Norway; Finn H. Andersen, ICU, Ålesund hospital, Norway; Sameer Maini, Medical ICU, Aalesund Hospital, Norway; Lutz Fehrle, ICU, Molde hospital, Norway; Mirosław Czuczwar, 2nd Department of Anesthesiology and Intensive Care Medical University of Lublin, Poland; Paweł Krawczyk, Department of Anaesthesiology and Intensive Care Medicine, Jagiellonian University Medical College, Poland; Mirosław Ziętkiewicz, Department of Anaesthesiology and Intensive Care Medicine, Jagiellonian University Medical College \& Thoracic Anaesthesia and Respiratory ICU, John Paul II Hospital, Poland; Łukasz R. Nowak, Maria Skłodowska-Curie Memorial Institute of Oncology, Cancer Centre, Poland; Katarzyna Kotfis,Department of Anesthesiology, Intensive Therapy and Acute Intoxications, University Hospital No. 2, Pomeranian Medical University in 
Szczecin, Poland; Katarzyna Cwyl, Anesthesia and Intensive Care Unit, Regional Health Center in Lubin, Poland; Ryszard Gajdosz, Faculty of medicine and Health Sciences Krakow University A.F. Modrzewski \&St.Raphael Hospital, Department of Anaesthesiology and Intensive Care, Poland; Jowita Biernawska, Pomeranian Medical University SPSK 1, Clinical Anesthesiology and Intensive Therapy PUM, Poland; Romuald Bohatyrewicz, Pomeranian Medical University SPSK 1, Clinical Anesthesiology and Intensive Therapy PUM, Poland; Ryszard Gawda, Department of Anesthesiology and Intensive Care, Opole University Hospital, Poland; Paweł Grudzień, Department of Anaesthesiology and Intensive Therapy, Edward Szczeklik Specialist Hospital in Tarnów, Poland; Paweł Nasiłowski, Department of Anaesthesiology and Intensive Therapy, Department of Anaesthesiology and Intensive Care, Gabriel Narutowicz Specialist Hospital in Kraków, Poland; Natalia Popek, Department of Anaesthesiology and Intensive Therapy, Stefan Żeromski Specialist Hospital in Kraków, Poland; Waldemar Cyrankiewicz, Department of Anaesthesiology and Intensive Therapy, Antoni Jurasz University Hospital No. 1 in Bydgoszcz, Poland; Katarzyna Wawrzyniak, Department of Anaesthesiology and Intensive Therapy, Antoni Jurasz University Hospital No. 1 in Bydgoszcz, Poland; Marek Wnuk, Department of Aanesthesiology and Intensive Therapy, John Paul II Memorial Hospital in Bełchatów, Poland; Dariusz Maciejewski, Faculty of Health Science, ATH Bielsko-Biała \& Department of Anaesthesiology and Intensive Therapy, Regional Hospital in Bielsko-Biała, Poland; Dorota Studzińska, Department of Anaesthesiology and Intensive Care, St. John Grande Hospital, Poland; Maciej Żukowski, Department of Anesthesiology, Intensive Therapy and Acute Intoxications, University Hospital No. 2, Pomeranian Medical University in Szczecin, Poland; Szymon Bernas, Department of Anaesthesiology and Intensive Therapy Centre for Artificial Extracorporeal Kidney and Liver Support, Dr Władysław Biegański Regional Specialist Hospital in Łódź, Poland; Mariusz Piechota, Department of Anaesthesiology and Intensive Therapy Centre for Artificial Extracorporeal Kidney and Liver Support, Dr Władysław Biegański Regional Specialist Hospital in Łódź, Poland; Centre for Artificial Extracorporeal Kidney and Liver Support, Poland; Wojciech Szczeklik, Department of Intensive Care and Perioperative Medicine, Jagiellonian University Medical College, Poland; llona Nowak-Kózka, Department of Intensive Care and Perioperative Medicine, Jagiellonian University Medical College, Poland; Jakub Fronczek, Department of Intensive Care and Perioperative Medicine, Jagiellonian University Medical College, Poland; Marta Serwa, Anaesthesia and Intensive Care Clinic, Central Clinical Hospital CKD, University Medical College in Łódź, Poland; Waldemar Machała, Anaesthesia and Intensive Care Clinic, Central Clinical Hospital CKD, University Medical College in Łódź, Poland; Jan Stefaniak, Department of Anaesthesiology and Intensive Therapy, Medical University of Gdańsk, Faculty of Medicine, Poland; Maria Wujtewicz, Department of Anaesthesiology and Intensive Therapy, Medical University of Gdańsk, Faculty of Medicine, Poland; Małgorzata Szymkowiak, Department of Anaesthesiology and Intensive Therapy, Józef Struś Specialist Hospital in Poznań, Poland; Barbara Adamik, Department of Anesthesiology and Intensive Therapy, Wrocław Medical University, Poland; Kamil Polok, Department of Intensive Care and Perioperative Medicine, Jagiellonian University Medical College, Poland; Anna Włudarczyk, Department of Intensive Care and Perioperative Medicine, Jagiellonian University Medical College, Poland; Jacek Górka, Department of Intensive Care and Perioperative Medicine, Jagiellonian University Medical College, Poland; Natalia Kozera, Department of Anesthesiology and Intensive Therapy, Wroclaw Medical University, Poland; Waldemar Goździk, Department of Anesthesiology and Intensive Therapy, Wroclaw Medical University, Poland; Nuno Catorze, UCIP, C. H. Médio TEJO, Portugal; Miguel Castelo Branco, Unidade de Cuidados Intensivos, Centro Hospitalar Cova da Beira, EPE, Portugal; Inês Barros, Unidade de Cuidados Intensivos Polivalente, Centro Hospitalar Tondela-Viseu, Portugal; Nelson Barros, Serviço Medicina Intensiva, Centro Hospitalar Trás-os-Montes e Alto Douro, Portugal; Andriy Krystopchuk, Intensive Care and Emergency Department, Centro Hospitalar do Algarve-Hospital de Faro, Portugal; Teresa Honrado, Unidade Cuidados INtensivos Polivalente, Hospital de São João, Portugal; Cristina Sousa, UCl, Hospital da Luz, Portugal; Francisco Munoz, UMI, Hospital do SAMS, Portugal; Marta Rebelo, UCIP, Hospital de Egas Moniz, Portugal; Rui Gomes, UCl, Hospital Garcia de Orta, Portugal; Jorge Nunes, Unidade de Cuidados Intensivos, Hospital Lusiadas Lisboa, Portugal; celeste dias, Neurocritical ICU, Hospital de São João, Portugal; Ana Margarida Fernandes, UCI Neurocríticos, Hospital S. José - CHLC EPE, Portugal; Cristina Petrisor, Anaesthesia and Intensive Care 1, Clinical Emergency County Hospital Cluj, Portugal; Bodolea Constantin, ATI, Municipal Hospital, Portugal; Vladislav Belskiy, Department of Anesthesiology and Intensive Care, Privolzhskiy District
Medical Center, Russia; Boris Boskholov, Dept of intensive care, Zhadkevich Clinical Hospital, Russia; Enver Rodriguez, UCl, General Universitario de Castellón, Spain; Sergio Rebollo, ICU, HGU Santa Lucia,Cartagena, Murcia, Spain; Gerardo Aguilar, Unidad de Reanimación - Surgical ICU, Hospital Clínico Universitario de Valencia, Spain; Gaspar Masdeu, Servei Medicina Intensiva, Hospital de Tortosa Verge de la Cinta, Spain; Marián Irazábal Jaimes, Critical Care Unit, Hospital General de Catalunya, Spain; Ángela Prado Mira, Medicina Intensiva, Hospital General Universitario de Albacete, Spain; Maria A. Bodi, General ICU, Hospital Universitari de Tarragona Joan XXIII, Spain; Jesus A. Barea Mendoza, Servicio de Medicina Intensiva, Hospital Universitario 12 de Octubre, Spain; Sonia López-Cuenca, Servicio de Medicina Intensiva y Grandes Quemados, Hospital Universitario de Getafe, Spain; Marcela Homez Guzman, ICU, Hospital Universitario del Henares, Spain; Jesús Rico-Feijoo, Postoperative Critical Care Unit and Reanimation, Hospital Universitario Río Hortega de Valladolid, Spain; Mercedes Ibarz, ICU Hospital Universitario Sagrado Corazon, Barcelona, Spain; Josep Trenado Alvarez, Intensive Care Department. UCI-Semicritics, Hospital Universitario Mutua Terassa, Spain; Rafael Kawati, central ICU, Akademiska sjukhuset, Sweden; Joakim Sivik, IVA Alingsås Lasarett, Alingsås Lasarett, Sweden; den; Joakim Sivik, IVA Alingsås Lasarett, Sweden; Jessica Nauska, Intensivvårdsavdelning 31, Blekingesjukhuset Karlskrona, Sweeden; Daniel Smole, IVA, Centralsjukhuset i Karlstad, Sweden; Fredric Parenmark, IVA, Gävle sjukhus, Sweden; Johanna Lyrén, Intensivvårdsavdelning, Hudiksvalls sjukhus, Gävleborg, Sweden; Katalin Rockstrohm, IVA, Kalmar Länssjukhus, Sweden; Sara Rydén, Karolinska ICU Huddinge, Karolinska University Hospital, Sweden; Martin Spångfors, Intensiven, Kristianstad, Sweden; Morten Strinnholm, ICU KungälvsHospital, Sweden; Sten Walther, Cardiothoracic ICU, Linköping University Hospital, Sweden; Lina De Geer, ICU, Linköping University Hospital, Sweden; Peter Nordlund, OP/IVA Kliniken, Länssjukhuset Ryhov, Sweden; Staffan Pålsson, Intensivvårdsavdelningen, Norrtälje, Sweden; Harald Zetterquist, IVA, Nyköpings lasarett, Sweden; Annika Nilsson, IVA, Örnsköldsviks hospital, Sweden; Karin Thiringer, ICU, Sahlgrenska University Hospital Mölndal, Sweden; Mårten Jungner, ICU SUS Malmö, Skane University Hospital, Sweden; Björn Bark, IVA Lund, Skåne University Hospital, Sweden; Berit Nordling, IVA Sundsvall, Sweden; Hans Sköld, ICU, Torsby Sjukhus, Sweden; Camilla Brorsson, ICU University Hospital Northern Sweden, Sweden; Stefan Persson, Intensivvårsdavdelningen USÖ, University hospital Örebro, Sweden; Anna Bergström, ICU Vrinnevi hospital, Sweden; Johan Berkius, ICU Västerviks hospital, Sweden; Johanna Holmström, ICU Västerås, Västmanlands hospital, Sweden; I. van Dijk, Intensive Care, Alrijne Ziekenhuis, The Netherlands; Lenneke E.M. Haas, Intensive Care, Diakonessenhuis Utrecht, The Netherlands; D.Ramnarain, Intensive Care, Elisabeth Tweesteden Hospital Tilburg, The Netherlands; Tim Jansen, Intensive Care, HagaZiekenhuis, The Netherlands; Fleur Nooteboom, IC LZR, Laurentius Ziekenhuis, The Netherlands; Peter HJ van der Voort, ICU OLVG, OLVG, The Netherlands; Dylan de Lange, Department of Intensive Care Medicine, UMC Utrecht, The Netherlands; Willem Dieperink, Department of Critical Care, University Medical Center Groningen, The Netherlands; Monique C. de Waard, Intensive Care Adults, VU University Medical Center Amsterdam, The Netherlands; Annemarie GE de Smet, Intensive Care Unit, University Medical Centre, University of Groningen, The Netherlands; Laura Bormans, Intensive Care, Zuyderland Medical Centrer, Heerlen, The Netherlands; Tom Dormans, Intensive Care, Zuyderland Medical Center, Heerlen, The Netherlands; Ged Dempsey, Critical Care Unit, Aintree University Hospital NHS Foundation Trust, UK; Shiju J Mathew, ICU, Alexandra Hospital, UK; Ashok S Raj, ICU, Barts Health NHS Trust, Whipps Cross Hospital, UK; Irina Grecu, ITU/HDU, Basingstoke and North Hampshire Hospital, UK; Jason Cupitt, Critical Care Unit, Blackpool Teaching Hospitals NHS Foundation Trust, UK; Tom Lawton, Critical Care Unit, Bradford Royal Infirmary, UK; Richard Clark, ICU, Central Manchester Foundation Trust, UK; Monica Popescu, ICU, Chelsea and Westminster Foundation Trust, West Middlesex University Hospital, UK; Nick Spittle, ICU, Chesterfield Royal Hospital, UK; Maria Faulkner, ICU, Countess of Chester Hospital NHS Foundation Trust, UK; Amanda Cowton, ICU, Darlington memorial Hospital (CDDFT), UK; Esme Elloway, ICU, Derriford Hospital, UK; Patricia Williams, Critical Care Unit, Dorset County Hospital, UK; Michael Reay, Critical Care Unit, Dudley Group of Hospitals NHSFT, Russells Hall Hospital, UK; Srikanth Chukkambotla, Critical Care Unit, East Lancashire Hospitals NHS Trust, UK; Ravi Kumar, CCU, East Surrey Hospital, UK; Nawaf Al-Subaie, ICU, Espsom and St Helier University Hospitals, UK; Linda Kent, Critical Care Unit, Fairfield General Hospital, UK; Tiina Tamm, ICU, Frimley Health, Wexham Park Hospital, UK; Istvan Kajtor, ICU, Frimley Park Hospital, UK; Karen Burns, ICU, Furness General, UK; Richard Pugh, Critical Care Unit, Glan Clwyd Hospital, UK; Marlies Ostermann, ICU, Guys and St Thomas Hospital, UK; 
Elisa Kam, ICU, Hillingdon Hospital, UK; Helen Bowyer, Critical Care Centre, Hinchingbrooke Healthcare NHS Trust, UK; Neil Smith, HICU 1\&2, Hull Royal Infirmary, UK; Maie Templeton, Critical Care UNIT, Imperial College Healthcare NHS Trust, UK; Jeremy Henning, ICU2\&3, James Cook Univeristy Hospital, UK; Kelly Goffin, ICU, James Paget University Hospital, UK; Ritoo Kapoor, K\&C ITU, Kent and Canterbury Hospital, UK; Shondipon Laha, CrCU, Lancashire Teaching Hospitals NHS Foundation Trust, UK; Phil Chilton, Critical Care Unit, Leighton Hospital, UK; Waqas Khaliq, ITU/HDU, Lewisham and Greenwich NHS Trust, UK; Alison Crayford, ITU/HDU, Maidstone, UK; Samantha Coetzee, ICU, Medway NHS Foundation Trust, UK; Moira Tait, Adult ICU, Musgrove Park, UK; Wendy Stoker, ICU, Northumbria Specialist Emergency Care Hospital, UK; Marc Gimenez, ICU, Papworth Hospital NHS Foundation Trust, UK; Alan Pope, Critical Care Unit, Peterborough City Hospital, UK; Julie Camsooksai, Critical Care Unit, Poole Hospital NHS Trust, UK; David Pogson, Department of Critical Care, Queen Alexandra Hospital Portsmouth, UK; Kate Quigley, ICU, Queen Elizabeth Hospital, UK; Jenny Ritzema, Critical Care Department, Queen Elizabeth Hospital, Gateshead, UK; Anil Hormis, Critical Care Unit, Rotherham NHS Foundation Trust, UK; Carole Boulanger, ICU, Royal Devon and Exeter NHS Foundation Trust, UK; M. Balasubramaniam, ICU and HCU, Royal Bolton NHS hospital trust, UK; Luke Vamplew, Critical Care Unit, Royal Bournemouth Hospital, UK; Karen Burt, Critical Care Unit, Royal Cornwall Hospital NHS Trust, UK; Daniel Martin, ICU, Royal Free London NHS Foundation Trust, UK; Irina Grecu, ICU, Royal Hampshire County Hospital, UK; Jayne Craig, ICU, Royal Lancaster Infirmary, UK; John Prowle, Adult Critical Care Unit, Royal London Hospital, UK; Nanci Doyle, ICU, Royal Surrey County Hospital, UK; Jonathon Shelton, Ward 38 ICU, Royal Victoria Infirmary, UK; Carmen Scott, Ward 18 ICU, Royal Victoria Infirmary, UK; Phil Donnison, ICU, Salisbury District Hospital, UK; Sarah Shelton, ICU, Sherwood Forest Hospitals NHS Foundation Trust, UK; Christian Frey, ITU/HDU, South Tyneside District Hospital, UK; Christine Ryan, GICU, St Georges Hospital, UK; Dominic Spray, Cardiothoracic ICU, St Georges Hospital, UK; Christine Ryan, Acute Dependency Unit, St Georges Hospital NHS Trust London, UK; Veronica Barnes, Neuro ICU, St Georges University Hospital NHS Foundation Trust, UK; Kerry Barnes, ITU, st helier hospital, UK; Stephanie Ridgway, Critical Care Unit, NHS Foundation Trust, Tameside General Hospital, UK; Rajnish Saha, Critical Care Unit, The Princess Alexandra NHS Hospital, UK; Linda Kent, ICU, The Royal Oldham Hospital, UK; Thomas Clark, ICU, Torbay Hospital, UK; James Wood, ICU, Tunbridge Wells Hospital, UK; Clare Bolger, General Intensive Care, Univeristy Hospital Southampton NHS Foundation Trust, UK; Christopher Bassford, General Critical Care, University Hospital Coventry, UK; Amanda Cowton, ICU, University hospital of North Durham, UK; john lewandowski, Critical Care Unit, University Hospital of North Tees, UK; Xiaobei Zhao, ICU (Level 6), Watford General Hospital/West Hertfortshire NHS trust, UK; Sally Humphreys, Critical Care, West Suffolk NHS Foundation Trust, UK; Susan Dowling, Ward 4E Critical Care unit, Whiston, UK; Neil Richardson, ICU, William Harvey Hospital, Ashford, UK; Andrew Burtenshaw, Critical Care Unit, Worcestershire Royal Hospital, UK; Carl Stevenson, ICU, Wye Valley NHS Trust, UK; Danielle Wilcock, Critical Care Unit, York Teaching Hospital NHS Foundation Trust, UK; Yuiry Nalapko, Anaesthesia and Intensive Care, Lugansk State Medical University, Ukraine.

\section{Authors' contributions}

$\mathrm{Ml}$ and $\mathrm{AA}$ designed the study. $\mathrm{MI}, \mathrm{AB}, \mathrm{LH}, \mathrm{BG}$, and $\mathrm{AA}$ performed the analyses and drafted and coordinated the manuscript. $A B$ performed the statistical analyses and helped with interpreting the results and writing the manuscript. HF was principal investigator of the VIP-1 study, provided his expertise, and made substantial contributions to the interpretation of the results and to drafting and revising the manuscript for important intellectual content. JF run the database and the eCRF. All other authors were country coordinators and validated the manuscript. All authors read and approved the final manuscript.

\section{Funding}

No specific funding was received, but the study was endorsed by the European Society of Intensive Care Medicine.

\section{Availability of data and materials}

The datasets generated and/or analysed during the current study are not publicly available due privacy issues of the study populations.

\section{Ethics approval and consent to participate}

An institutional research ethics board at each study site approved the study.

Most patients provided written informed consent before inclusion in the study but in some countries given its non-interventional nature, informed consent was waived.

\section{Consent for publication}

Not applicable.

\section{Competing interests}

None of the authors have competing interests; all authors have read the current "Instructions to authors" and accept the conditions posed therein. This manuscript is original and has not been and will not be simultaneously submitted elsewhere for publication. None of the material from this study is included in another manuscript, has been published previously, or has been posted on the internet.

\section{Author details}

${ }^{1}$ Department of Intensive Care Medicine, Hospital Universitario Sagrat Cor, Viladomat 288, 08029 Barcelona, Spain. ${ }^{2}$ Assistance Publique-Hôpital de Paris, Hôpital Saint-Antoine, Service de Réanimation Médicale, 75012 Paris, France. ${ }^{3}$ Department of Intensive Care Medicine, Diakonessenhuis Utrecht, Utrecht, The Netherlands. ${ }^{4}$ Department of Intensive Care Medicine, Hospital Universitario General de Cataluña, Sant Cugat del Valles, Spain. ${ }^{5}$ Department of Anaesthesia and Intensive Care, Haukeland University Hospital, Bergen, Norway.

${ }^{6}$ Department of Intensive Care Medicine, University Medical Center, University of Utrecht, Utrecht, The Netherlands. ${ }^{7}$ Department of Rehabilitation Hospital Ancelle di Cremona, Cremona, Italy. ${ }^{8}$ Geriatric Research Group, Brescia, Italy. ${ }^{9}$ Department of Anaesthesia and Intensive Care, Ålesund Hospital, Ålesund, Norway. ${ }^{10}$ NTNU, Department of Circulation and Medical Imaging, Trondheim, Norway. ${ }^{11}$ Laboratorio di Epidemiologia Clinica, Centro di Coordinamento GiViTI Dipartimento di Salute Pubblica, IRCCS - Instituto di Ricerche Farmacologiche "Mario Negri" Ranica, Bergamo, Italy. ${ }^{12}$ Department of Anesthesia and Intensive Care Medicine, Humanitas Clinical and Research Center - IRCCS, Via Alessandro 13 Manzoni, 56, 20089 Rozzano, MI, Italy. ${ }^{13}$ Department of Biomedical Sciences, Humanitas University, Pieve Emanuele, MI, Italy. ${ }^{14}$ Department of Anaesthesia and Intensive Care Medicine, Aarhus University Hospital, Aarhus, Denmark. ${ }^{15}$ ASST Grande Ospedale Metropolitano Niguarda, Milan, Italy. ${ }^{16}$ Department of Cardiology, Pulmonology and Angiology, University Hospital, Düsseldorf, Germany. ${ }^{17}$ Mater Misericordiae University Hospital, Dublin, Ireland. ${ }^{18}$ Unidade de Cuidados Intensivos Neurocríticos e Trauma, Hospital de São José, Centro Hospitalar de Lisboa Central, Faculdade de Ciência Médicas de Lisboa, Nova Médical School, Lisbon, Portugal. ${ }^{19}$ Department of Intensive Care 1K12IC, Ghent University Hospital, Ghent, Belgium. ${ }^{20}$ Karolinska University Hospital, Stockholm, Sweden. ${ }^{21}$ Department of Anaesthesiology, Pharmacology and Intensive Care, Geneva University Hospitals, Geneva, Switzerland. ${ }^{22}$ Intensive Care and Perioperative Medicine Division, Jagiellonian University Medical College, Kraków, Poland. ${ }^{23}$ Kardinal Schwarzenberg Hospital, Schwarzach, Austria. ${ }^{24}$ St George's University Hospital, London, UK. ${ }^{25}$ Intensive Care Unit General Hospital of Larissa, Larissa, Greece. ${ }^{26}$ Sorbonne Université, INSERM, Institut Pierre Louis d'Epidémiologie et de Santé Publique, AP-HP, Paris, France. ${ }^{27}$ Department of Intensive Care Medicine, CIBER Enfermedades Respiratorias, Corporacion Sanitaria Universitaria Parc Tauli, Autonomous University of Barcelona, Sabadell, Spain. ${ }^{28}$ Department of Clinical Medicine, University of Bergen, Bergen, Norway.

Received: 9 October 2019 Accepted: 4 May 2020

Published online: 13 May 2020

\section{References}

1. Flaatten $H$, De Lange DW, Morandi A, et al. The impact of frailty on ICU and 30-day mortality and the level of care in very elderly patients ( $\geq 80$ years). Intensive Care Med. 2017;43:1820-8.

2. Ihra GC, Lehberger J, Hoechrieser H, et al. Development of demographics and outcome of very old critically ill patients admitted to intensive care units. Intensive Care Med. 2012;38:620-6.

3. Lerolle N, Trinquart L, Bornstain C, Tadie JM, Imbert A, Diehl JL, Fagon J, Guerot E. Increased intensity of treatment and decreased mortality in elderly patients in an intensive care unit over a decade. Crit Care Med. 2010;38:59-64. 
4. Auclin E, CharlesNelson A, Abbar B, et al. Outcomes in elderly patients admitted to the intensive care unit with solid tumors. Ann Intensive Care. 2017;7:26-34

5. Tabah A, Philippart F, Timsit JF, Willems V, et al. Quality of life in patients aged 80 or over after ICU discharge. Crit Care. 2010;14(1):R2.

6. Leblanc G, Boumendil A, Guidet B. Ten things to know about critically ill elderly patients. Intensive Care Med. 2017;43:217-9.

7. Nguyen Y, Angus D, Boumendil Guidet B. The challenge of admitting the very elderly to intensive care. Ann Intensive Care. 2011;1:29-36.

8. Annane D, Aegerter P, Jars-Gincestre MC, et al. Current epidemiology of septic shock: the CUB-Rea Network. Am J Respir Crit Care Med. 2003;168:165-72

9. Angus DC, Linde-Zwirble WT, Lidicker J, Clermont G, Carcillo J, Pinsky MR. Epidemiology of severe sepsis in the United States: analysis of incidence, outcome and associated cost of care. Crit Care Med. 2001;29:1303-10.

10. Martin GS, Mannino DM, Moss M. The effect of age on the development and outcome of adult sepsis. Crit Care Med. 2006;34:15-21.

11. Ferrer R, Artigas A, Levy MM, Edusepsis Study Group, et al. Improvement in process of care and outcome after a multicenter severe sepsis educational program in Spain. JAMA. 2008;299:2294-303.

12. Brun-Buisson C, Meshaka P, Pinton P, EPISEPSIS Study Group, et al. EPISEPSIS: a reappraisal of the epidemiology and outcome of severe sepsis in French intensive care units. Intensive Care Med. 2004;30(4):580-8.

13. Finfer $S$, Bellomo R, Lipman J, et al. Adult-population incidence of severe sepsis in Australian and New Zealand intensive care units. Intensive Care Med. 2004;30(4):589-96.

14. Singer M, Deutschman CS, Seymour CW, et al. The third international consensus definitions for sepsis and septic shock (Sepsis-3). JAMA. 2016;315:801-10.

15. Stevens M, Samaha GJ, Chong SG, Casserly BP, Levy MM. Sepsis in the elderly. In: Guidet B, Artigas Raventos A, editors. Personnes âgées et reanimation., Références en reanimationParis: Springer; 2012. p. 227-42.

16. Biston P, Aldecoa C, Devriendt J, Madl C, Chochrad D, Vincent JL, et al. Outcome of elderly patients with circulatory failure. Intensive Care Med. 2014:40:50-6.

17. Iwashyna TJ, Ely EW, Smith DM, Langa KM. Long-term cognitive impairment and functional disability among survivors of severe sepsis. JAMA. 2010;304:1787-94.

18. Oeyen S, Vermassen J, Piers R, Benoit D, Annemans L, Decruyenaere J. Critically ill octogenarians and nonagenarians: evaluation of long-term outcomes, posthospital trajectories and quality of life one year and seven years after ICU discharge. Minerva Anestesiol. 2017;83:598-609.

19. Heyland DK, Garland A, Bagshaw SM, et al. Recovery after critical illness in patients aged 80 years or older: a multi-center prospective observational cohort study. Intensive Care Med. 2015;41:1911-20.

20. Heyland D, Cook D, Bagshaw SM, et al. The very elderly admitted to ICU: a quality finish? Crit Care Med. 2015;43:1352-60.

21. Flaatten $H$, De Lange DW, Artigas A, Bin D, Moreno R, et al. The status of intensive care medicine research and a future agenda for very old patients in the ICU. Intensive Care Med. 2017;43:1319-28.

22. Vincent JL, Moreno R, Takala J, Williams S, de Mendonça A, Bruining $H$, et al. The SOFA (Sepsis-related Organ Failure Assessment) score to describe organ dysfunction/failure. On behalf of the Working Group on Sepsis-related Problems of the European Society of Intensive Care Medicine. Intensive Care Med. 1996:22:707-10.
23. Rockwood K, Song X, Macknight C, Bergman H, Hogan DB, et al. A global clinical measure of fitness and frailty in elderly people. CMAJ. 2005:173:489-95.

24. Dugué $A E$, Pulido M, Chabaud S, Belin L, Gal J. How to deal with interval-censored data practically while assessing the progression-free survival: a step-by-step using SAS and R software. Clin Cancer Res. 2016;22(03):5629-35.

25. Cole C, Hernan M. Adjusted survival curves with inverse probability weights. Comput Methods Programs Biomed. 2004;75:45-9.

26. Therneau TM, Crowson CS, Atkinson EJ. (2015) Adjusted survival curves. https://cran.r-project.org/web/packages/survival/vignettes/adjcurve.pdf.

27. Andersen FH, Flaatten $\mathrm{H}$, Klepstad P, Tomild U, Kvale R. Long-term survival and quality of life after intensive care for patients 80 years of age or older. Ann Intensive Care. 2015;5:13. https://doi.org/10.1186/s1361 3-015-0053-0.

28. Keet O, Chisholm S, Goodson J, Browne T. A retrospective observational study of mortality rates in elderly patients with shock in a New Zealand district hospital ICU. N Z Med J. 2017;130:29-34.

29. Haas LEM, Van Dillen LS, de Lange DW, Van Dijk D, Hamker ME. Outcome of very old patients admitted to the ICU for sepsis: a systematic review. Eur Geriatr Med. 2017:8:446-53.

30. Nielsson MS, Christiansen CF, Johansen MB, Rasmussen BS, Tonessen E, Norgaard M. Mortality in elderly patients: a cohort study. Acta Anaesthesiol Scand. 2014;58:19-26.

31. Bagshaw SM, Stelfox HT, McDermid RC, et al. Association between frailty and short- and long-term outcomes among critically ill patients: a multicentre prospective cohort study. CMAJ. 2014;186:E95-102.

32. Jung C, Wernly B, Muessig JM, et al. A comparison of very old patients admitted to intensive care unit after acute versus elective surgery or intervention. J Crit Care. 2019;52:141-8.

33. De Rooij SE, Govers AC, Korevaar JC, Giesbers AW, Levi M, De Jonge E. Cognitive, functional and quality-of-life outcomes of patients aged 80 and older who survived at least 1 year after planned surgery or medical intensive care treatment. J Am Geratric Soc. 2008;56:816-22.

34. Mark NM, Rayner SG, Lee NJ, Curtis JR. Global variability in withholding and withdrawal of life-sustaining treatment in the intensive care unit: a systematic review. Intensive Care Med. 2015;41:1572-85.

35. Ferrand $E$, Robert $R$, Ingrand $P$, Lemaire F, French LATARREA Group. Withholding and withdrawal of life support in intensive-care units in France: a prospective survey. French LATARREA Group. Lancet. 2001;357:9-14.

36. Weimer JM, Nowacki AS, Frontera JA. Withdrawal of life sustaining therapy in patients with intracranial hemorrhage: self-fulfilling prophecy or accurate prediction of outcome? Crit Care Med. 2016:44:1161-72.

37. Guidet B, Flaatten H, Boumendil A, Morandi A, Andersen FH, Artigas A, Bertolini G, On behalf of the VIP1 study group, et al. Withholding or withdrawing of treatment in very elderly patients ( $\geq 80$ years) admitted to the intensive care unit. Intensive Care Med. 2018;44(7):1027-38.

38. Guidet B, Vallet H, Boddaert J, De Lange DW, Morandi A, et al. Caring for the critically ill patients over 80: a narrative review. Ann Intensive Care 2018;8:114-29.

\section{Publisher's Note}

Springer Nature remains neutral with regard to jurisdictional claims in published maps and institutional affiliations. 